NOTE

\title{
Numerical simulation to resolve the issue of downstream migration of the Japanese eel
}

\author{
Shingo Kimura ${ }^{1, *}$, Kristofer Döös ${ }^{2}$, Andrew C. Coward ${ }^{3}$ \\ 'Ocean Research Institute, University of Tokyo, Nakano, Tokyo 164-8639, Japan \\ ${ }^{2}$ Meteorologiska Institutionen, Stockholms Universitet, 10691 Stockholm, Sweden \\ ${ }^{3}$ Southampton Oceanography Centre, Empress Dock, Southampton SO14 3ZH, United Kingdom
}

\begin{abstract}
In 1991 an expedition of a Japanese research vessel discovered that the spawning ground of the Japanese eel is located in the North Equatorial Current (NEC) in the Pacific Ocean. Several unanswered questions about the distribution of the eel and their larvae downstream of the NEC, however, remain and are unlikely to be resolved by observations alone. Three such questions are about (1) previous misdetermination of spawning ground, (2) the large larval catch off the west coast of Taiwan, not off the east coast, and (3) the low abundance of larvae in Korean coastal waters. It had been thought that the physiological behavior of adult and larval eels and their adaptation to different environments determined their distributions. However, we have demonstrated that these issues can be explained by the water circulation in the North Pacific.
\end{abstract}

KEY WORDS: Japanese eel - Larval migration - North Equatorial Current - Numerical simulation - OCCAM

An expedition of the research vessel 'Hakuho-maru' of the Ocean Research Institute, University of Tokyo, in 1991 discovered that the spawning ground of the Japanese eel Anguilla japonica is located in the North Equatorial Current (NEC), west of the Mariana Islands at a salinity front near $15^{\circ} \mathrm{N}, 140^{\circ} \mathrm{E}$ (Tsukamoto 1992 , Kimura et al. 1994). Determination of the spawning ground was based on 2 facts: firstly, larvae collected at the location were only 2 to 3 wk old and, secondly, the averaged current velocity in the NEC was appropriate for distributing the larvae to the Kuroshio region before they reached their metamorphosis stage. In addition, the absence of large genetic differences among the Japanese eel caught in Japan, China, Taiwan and Korea (Taniguchi \& Numachi 1978, Sang et al. 1994) suggests that the region west of the Mariana

•E-mail: kimuras@ori.u-tokyo.ac.jp
Islands is the only spawning ground for the Japanese eel. Fig. 1 shows the ocean circulation around the spawning and nursery grounds of Japanese eel in East Asia. After entirely passive westward transport by the NEC, the larvae must transfer from the NEC to the strong northward-flowing Kuroshio at the terminus of the NEC. Transport to the Mindanao Current leads to a death migration because the adult Japanese eel does not distribute downstream of this current.

To explain how the leaf-like, tiny eel larvae (leptocephali) migrate $3000 \mathrm{~km}$ from the spawning ground in the NEC to their growth habitat in East Asia, a model including the effects of trade winds and the salinity front was proposed (Kimura et al. 1994). The model concluded that when the physical and geophysical conditions were well matched with the timing of the

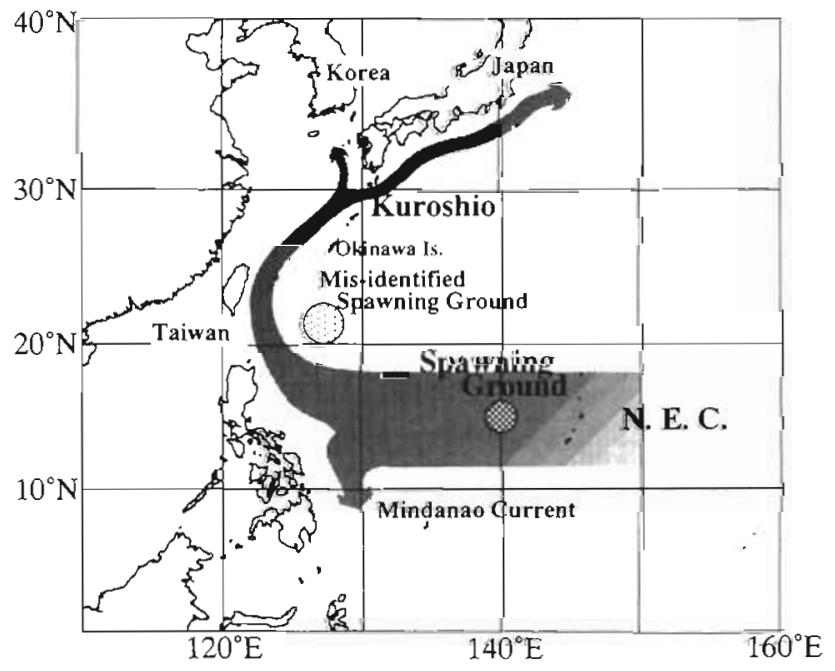

Fig. 1. Ocean circulation around spawning and nursery grounds of Japanese eel in East Asia. NEC: North Equatorial Current 
onset of vertical migration large-scale eel migration could result. While the model does not show all the routes and mechanisms of the larval migration of the Japanese eel, it does indicate that a complicated strategy is necessary for the successful completion of migration.

Further physical and biological observations are necessary to clarify the migration mechanism. Such future observations could clarify the individual behavior of the Japanese eel larvae including their physiological characteristics in the NEC. However, some unanswered questions about their distributions downstream of the NEC are unlikely to be resolved by observations alone. This is because the local ocean circulation has a considerable effect on the larval distribution. Three such questions are:

(1) Why was the location of the spawning ground previously estimated to be south of the Okinawa Islands (Matsui 1957)?

(2) Why have the larvae been caught mainly off the west coast of Taiwan (Tzeng 1987), despite the fact that the main stream of the Kuroshio flows to the east of Taiwan?

(3) Why has the abundance of Japanese eel in Korean coastal waters been considerably smaller than that in Japanese coastal waters (Tsukamoto \& Otake 1995), even though the current circulation around the Japanese Islands suggests a greater likelihood that the larvae would be transported to the Korean coasts?

In order to help resolve these questions and to confirm how physical factors affect the larval distribution of the Japanese eel in East Asia, we conducted numerical simulations of the transport of the larvae from their spawning ground. Modern, high resolution, physical ocean models are proving capable of reproducing the ocean circulation with a high degree of accuracy. By treating the larvae as passively drifting particles, such models provide useful tools for investigating patterns of larval migration.

Methods. A Bryan-Cox-Semtner numerical model known as OCCAM IOcean Circulation and Climate Advanced Model; Webb 1995, Webb et al. 1997, Saunders et al. 1999) developed at the Southampton Oceanography Centre in the United Kingdom was used. The model has a realistic topography with 36 levels in the vertical ranging from $20 \mathrm{~m}$ thick at the surface increasing to $250 \mathrm{~m}$ thick at depth. The model has global coverage with a spatial resolution of $0.25^{\circ}$ and a baroclinic time step of $15 \mathrm{~min}$. Wind stresses, interpolated from an annual cycle of 12 monthly fields are applied at the surface and the surface temperature and salinity values are relaxed towards monthly climatological values. For diffusion of tracers, $10^{5} \mathrm{~cm}^{2} \mathrm{~s}^{-1}$ is adopted as the horizontal eddy diffusivity. The model was initialized with climatological conditions and integrated for 14 model years. An annual average flow-field was constructed from the last 4 model years integration and this was used to calculate larvae trajectories using an off-line trajectory-tracking method (Döös 1995, Blanke \& Raynaud 1997). For the purposes of this work, 93 particles were deployed at $140^{\circ} \mathrm{E}$, $15^{\circ} \mathrm{N}$, initially distributed evenly from the surface to $100 \mathrm{~m}$ depth, and tracked for $5 \mathrm{yr}$. In this present study, the active vertical migration of larvae themselves was not considered since the behavior was not confirmed quantitatively and this study was a first step to understand their migration.

Results and discussion. Figs. 2 \& 3 show larval trajectories released at the spawning ground $\left(15^{\circ} \mathrm{N}\right.$, $140^{\circ} \mathrm{E}$ ) with time and depth changes, respectively. Initially, the majority of the larvae were transported westward in the NEC. However, those inhabiting the surface layer were transported northwestward by the Ekman transport and finally entrained into a subgyre located south of the Okinawa Islands. The subgyre is created by the Subtropical Countercurrent and a westward flow located just south of the countercurrent, and surface water exchange among the subgyre is almost nonexistent (Hasunuma \& Yoshida 1978). Many of these particles in this simulation are trapped within the subgyre for more than 1 yr. This result could explain why considerably larger size leptocephali were collected in and near the subgyres (Tanaka 1975, Tabeta \& Konishi 1986, Kajihara 1988, Tabeta \& Mochioka 1988 ) and illustrates how the existence of the subgyres have previously led to the mis-determination of the spawning ground.

The westward moving particles, however, stayed in a layer deeper than $40 \mathrm{~m}$ in the NEC and contributed to the eventual migration to the Japanese coasts. The difference between the 2 typical trajectories is clearly attributable to direct effects of the wind, as has been noted previously (Kimura et al. 1994). In the present simulation, particles transported northwestward but not entrained into the subgyre also contributed to recruitment in the Japanese coasts. Therefore, weak trade winds can also affect the success of the migration.

Although the main stream of the Kuroshio passes to the east of Taiwan, half the particles were transported into the region west of Taiwan in our numerical simulation. This result indicates that the water exchange in the surface layer around Taiwan is directly influenced by the wind-driven flow and the density gradient, and these influences cause larval transport into the western region. This high possibility of larval transport into the Chinese continental shelf may explain the high abundance of Japanese eel larvae in the western region of Taiwan.

According to the simulated results, larvae took more than 1 yr to reach the Korean coasts while larvae took 


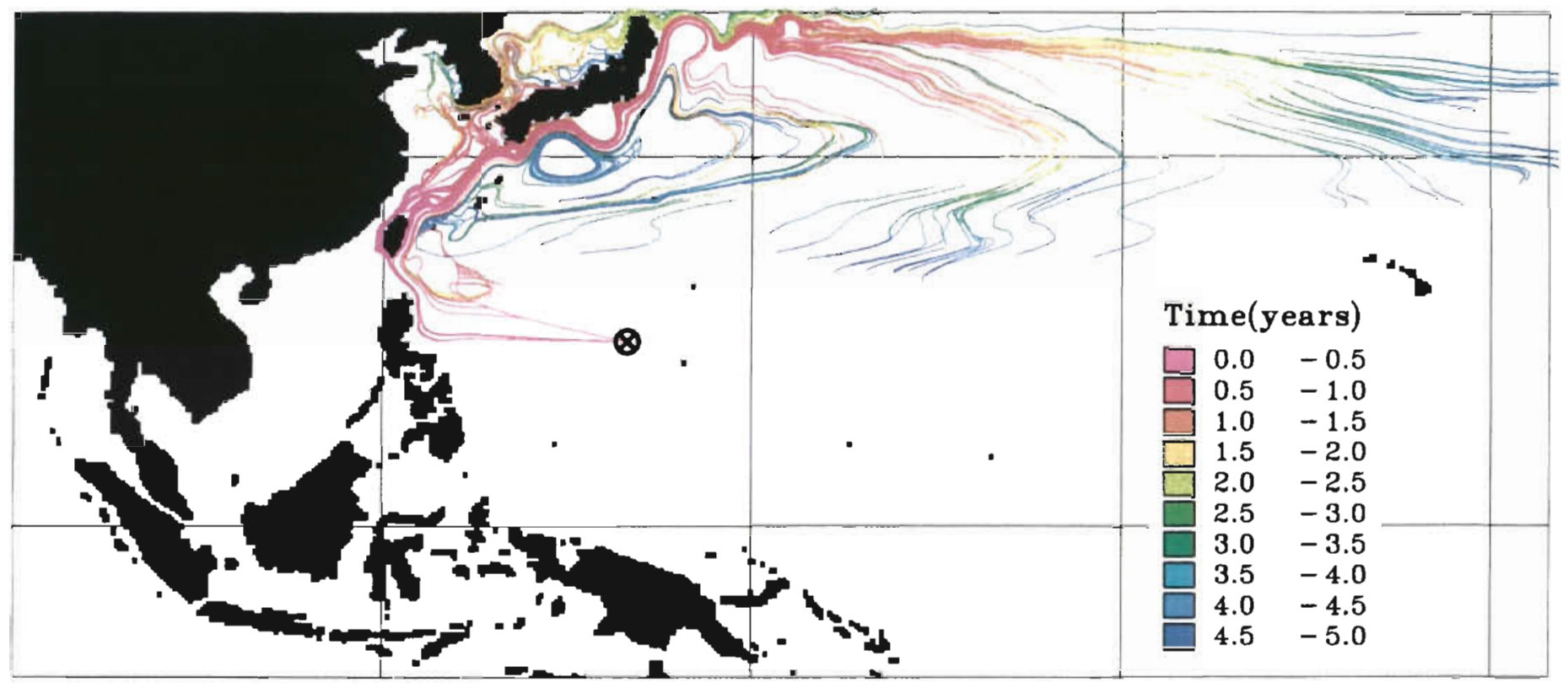

Fig. 2. Larval trajectories released at the spawning ground with time change

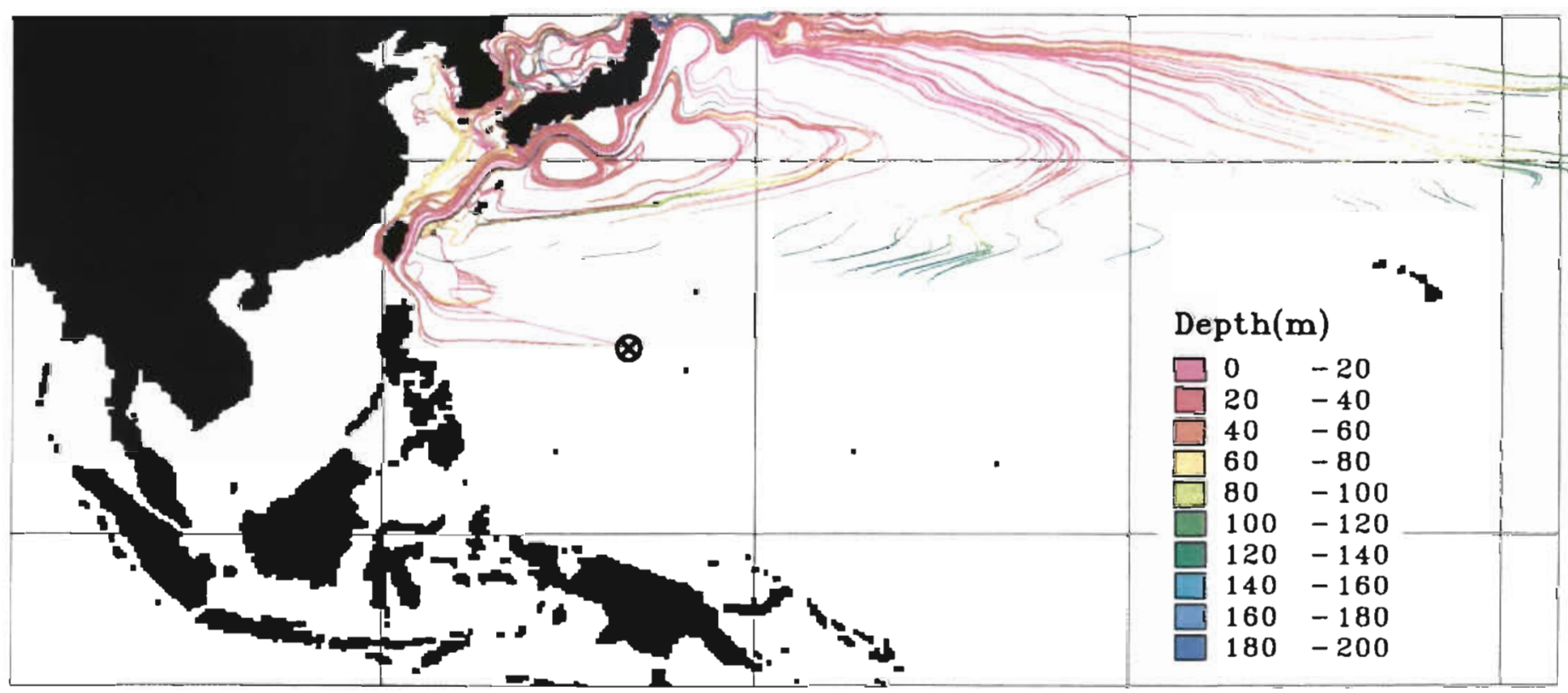

Fig. 3. Same as Fig. 2 but with depth change

only 6 mo to reach Japanese coastal waters. The averaged spawning season of the Japanese eel is estimated to be July (Tsukamoto 1990). Before reaching the Taiwan and Japanese coasts, they have to metamorphose from leptocephali to glass eel (approximately 4 to $5 \mathrm{mo}$ after birth) and to spend a further 1 to 2 mo at sea (Cheng \& Tzeng 1996, Arai et al. 1997). The simulated duration of migration from the spawning ground to the
Japanese coasts is consistent with these observations. In fact, the larvae in the Kuroshio region are usually caught in winter, almost exactly 6 mo after the spawning season (Tzeng 1985, Tsukamoto 1990). However, the duration of migration to the Korean coasts is too long for the larvae to reach the river mouths soon after completing metamorphosis. Since this means that the opportunity to travel up the nursery rivers is missed, 
most of metamorphosed eel larvae cannot enter Korean rivers.

Conclusion. In this study, we have demonstrated that 3 unresolved questions about larval distribution of the Japanese eel can be explained by water circulation in the North Pacific. It had been thought that physiological behavior of the adult and larval eels and their adaptation to different environments determined their distributions. Of course, the application of physical numerical simulations to biological studies should be done with care and must involve an in-depth understanding of the biological factors concerned. In view of this, we cannot neglect the effect which ecological and physiological factors have on the eels when considering the problems concerning their distributions. However, our study strongly indicates that ocean circulation plays an important role in their distribution and this exercise is able to settle problems which cannot be explained by observations alone.

Acknowledgements. The authors wish to thank Dr Peter Killworth, Dr David Webb and Dr John Shepherd for kindly providing a chance to conduct this corroborative study using results from OCCAM.

\section{LITERATURE CITED}

Arai T, Otake T, Tsukamoto K (1997) Drastic changes in otolith microstructure and microchemistry accompanying the onset of metamorphosis in the Japanese eel Anguilla japonica. Mar Ecol Prog Ser 161:17-22

Blanke B, Raynaud S (1997) Kinematics of the Pacific Equatorial Undercurrent: a Eulerian and Lagrangian approach from GCM results. J Phys Oceanogr 27:1038-1053

Cheng PW, Tzeng WN (1996) Timing of metamorphosis and estuarine arrival across the dispersal range of the Japanese eel Anguilla japonica. Mar Ecol Prog Ser 131:87-96

Döös K (1995) Inter-ocean exchange of water masses. J Geophys Res 100:13499-13514

Hasunuma K, Yoshida K (1978) Splitting of the subtropical gyre in the western north Pacific. J Oceanogr Soc Jpn 34 : $160-172$

Kajihara T (1988) Distribution of Anguilla japonica leptocephali in the Western Pacific during September 1986. Nippon Suisan Gakkaishi 54:929-933

Editorial responsibility: Otto Kinne (Editor), Oldendorf/Luhe, Germany
Kimura S, Tsukamoto K, Sugimoto T (1994) A model for the larval migration of the Japanese eel: roles of the trade winds and salinity front. Mar Biol 119:185-190

Matsui I (1957) On the records of a leptocephalus and catadromous eels of Anguilla japonica in the waters around Japan with a presumption of their spawning places. J Shimonoseki Coll Fish 7:151-167

Sang TK, Chang HY, Chen CT, Hui CF (1994) Population structure of the Japanese eel. Anguilla japonica. Mol Biol Evol 11:250-260

Saunders PM, Coward AC, de Cuevas BA (1999) The circulation of the Pacific Ocean seen in a Global Ocean Model (OCCAM). J Geophys Res (in press)

Tabeta O, Konishi Y (1986) An anguillid leptocephalus Anguilla japonica from the waters south of Miyako Island, Okinawa, Japan. Bul Jpn Soc Sci Fish 52:1935-1937

Tabeta O. Mochioka N (1988) Anguillid leptocephali from the waters south of Okinawa and east of Taiwan and Luzon, Western North Pacific, in 1986. Nippon Suisan Gakkaishi. 54:935-940

Tanaka S (1975) Collection of leptocephali of the Japanese eel in waters south of the Okinawa Island. Bull Jpn Soc Sci Fish 41:129-136

Taniguchi N, Numachi K (1978) Genetic variation of 6-phosphogluconate dehydrogenase, isocitrate dehydrogenase, and glutamic-oxaloacetic transaminase in the liver of Japanese eel. Bull Jpn Soc Sci Fish 44:1351-1355

Tsukamoto K (1990) Recruitment mechanism of iłıe êei. Anguilla japonica, to the Japanese coast. J Fish Biol 36: $659-671$

Tsukamoto K (1992) Discovery of the spawning area for Japanese eel. Nature 356:789-791

Tsukamoto $K_{1}$ Otake I (1995) Japanese eel population and human impact on the resources. In: Soemodihardjo $S$. Tsukamoto K, Romimohtarto K (eds) Proc 4th LIPI-JSPS Joint Seminar on Mar Sci, 15-1.8 November 1994. LIPIJSPS, Jakarta, p 85-89

Tzeng WN (1985) Immigration timing and activity rhythms of the eel, Anguilla japonica, elvers in the estuary of northern Taiwan, with emphasis on environmental influences. Bull Jpn Soc Fish Oceanogr 47/48:11-28

Tzeng WN (1987) Migration of elvers and environmental factors. In: Sugimoto T, Ishino $M$, Sugiura K, Nakata H (eds) Environmental fisheries oceanography. Koseisyakoseikaku, Tokyo, p 127-133

Webb DJ (1995) The vertical advection of momentum in Bryan-Cox-Semtner ocean general circulation models. $J$ Phys Oceanogr 25:3186-3195

Webb DJ, Coward AC, de Cuevas BA, Gwilliam CS (1997) A multiprocessor ocean general circulation model using message passing. J Atmos Ocean Tech 14:175-183

Submitted: February 26, 1999; Accepted: July 5, 1999 Proots received from author(s): August 16, 1999 